\title{
Correction to: Heterogeneous effects of remittances and institutional quality in reducing environmental deficit in the presence of EKC hypothesis: a global study with the application of panel quantile regression
}

\author{
Muhammad Usman $^{1}$ (D) - Atif Jahanger ${ }^{2}$ (D) \\ Published online: 5 April 2021 \\ (C) Springer-Verlag GmbH Germany, part of Springer Nature 2021
}

Correction to: Environmental Science and Pollution Research https://doi.org/10.1007/s11356-021-13216-x

The correct presentation of Eqs. 10 and 11 is revised in the original published paper.

The original article has been corrected.

Publisher's note Springer Nature remains neutral with regard to jurisdictional claims in published maps and institutional affiliations.

The online version of the original article can be found at https://oi.org/ 10.1007/s11356-021-13216-x

$\triangle$ Atif Jahanger

atif_jahanger@hotmail.com

Muhammad Usman

usman399jb@gmail.com

1 Department of Economics, Government College University Faisalabad, Faisalabad 38000, Pakistan

2 School of Economics, Zhongnan University of Economics and Law, Wuhan 430073, China 